\title{
The effect of nitric oxide on the pressure of the acutely obstructed ureter
}

\author{
Yan Xingyu - Tan Guoliang • Cai Youmei • \\ Wang Honggen · Guo Yihong · Chen Junyi
}

Received: 21 June 2010/Accepted: 2 June 2011/Published online: 22 June 2011

(C) The Author(s) 2011. This article is published with open access at Springerlink.com

\begin{abstract}
Acute ureteral obstruction leads to changes in pressure inside the ureter, interrupting ureter function. The aim of our study is to explore the relationship between nitric oxide (NO) concentration and pressure in the ureter and to observe the effects of nitric oxide on the revival of renal function. We created the animal models by embedding balloons in the lower ureters of anesthetized dogs and expanding them to simulate acute ureteral obstruction. First, the test animals were pre-treated intravenously with different doses of L-NAME (non-selective nitric oxide synthase inhibitor) to inhibit nitric oxide synthase (NOS), and $10 \mathrm{~min}$ later, each subject was administered an intravenous dose of isoproterenol $(10 \mu \mathrm{g} / \mathrm{kg})$. We measured ureter pressure (UP), total and peak concentrations of NO (using an NO monitor, model inNO-T) in ureteral urine, and the volume of the urine (UFV) leaking from the balloon edge. After a certain amount of time had elapsed, it became clear that the dose of L-NAME was inversely related to the total and peak concentrations of NO, the rate of change in UP, and the volume of urine produced. We conclude that L-NAME prevents the NOS from inhibiting the release of NO, then inhibits the effect of isoproterenol reducing the pressure of the acute obstructive ureter. Inversely, we think that NO can reduce the pressure of the acute obstructive ureter and make the obstructive ureter recanalization. And when more the concentration of nitric oxide, the more the pressure will be reduced, and more urine will be collected.
\end{abstract}

Y. Xingyu · T. Guoliang $(\bowtie) \cdot$ C. Youmei · W. Honggen ·

G. Yihong - C. Junyi

The Second Affiliated Hosipital of Fujian Medical University, Quanzhou, Fujian, China

e-mail: annan1125@sina.com
Keywords Dogs - Nitric oxide $\cdot$ Nitric oxide synthase Ureter $\cdot$ Obstruction $\cdot$ Pressure

\section{Introduction}

Acute ureteral obstruction is a common complication of other conditions studied in clinical urology, such as urinary tract stones, ureteropelvic junction obstruction (UPJO), and the complete and incomplete ureteral obstruction caused by postoperative tissues adhesion. Acute ureteral obstruction leads to changes in pressure inside the ureter, interrupting ureter function $[1,2]$.

Recent research has found that there are nitric oxide synthases (NOS) existing in mammals' ureteral smooth muscle and urothelial tissues [3-5]. Activation of NOS can stimulate the release of nitric oxide (NO). As an endothelium-derived relaxing factor (EDRF), NO can cause the vascular smooth muscle to relax, thereby reducing blood pressure [6]. It has been reported that the input of exogenous NO into the vitro organization of mammalian ureters apparently relaxed ureteral smooth muscle and reduced muscle tension. It has also been reported that the administration of adrenergic receptor agonists to the ureteral tissue can cause detectable increases in NO concentration. From this, it can be concluded that the relaxing of ureteral smooth muscle can activate NOS, thus stimulating the release of NO [7].

In this experiment, we embedded a balloon in the lower ureter and then progressively expanded it until complete ureter obstruction was achieved. Then, while regulating the NOS activity by drugs to affect the release of $\mathrm{NO}$, we observed the relationship between the pressure and the concentration of NO in the acutely obstructed ureter. 


\section{Materials and methods}

Animals

Healthy adult mixed-breed dogs, 25, were fed individually and kept in house (at a room temperature of about $26^{\circ} \mathrm{C}$ and humidity $55 \%$ ) for about 2 weeks before the experiment began, to ensure that they had adapted to the local environment.

Development of the animal model of acute ureteral obstruction

The animals were anesthetized with sodium pentobarbital (30 mg/kg, 3\%) by intraperitoneal injection. Tracheotomy was performed immediately, and positive pressure ventilation established (frequency of ventilator maintained at 15 times $/ \mathrm{min}, 20 \mathrm{ml} / \mathrm{kg}$ ). The dogs were secured to the experimental table and physiological saline $(15 \mathrm{ml} / \mathrm{kg} / \mathrm{h})$ was infused intravenously to ensure a stable flow of urine. Neck incisions were made and expanded and the left internal carotid artery was used to monitor the invasive blood pressure and heart rate. A small incision was made on the left midsection to provide access to the left kidney, and a small incision was made on the lateral process edge of the kidney. A catheter of about $5 \mathrm{~cm}$ was inserted through the ureter connecting on one end with a three-way pipe that in turn connected to the transducer, the transducer connected to the recorder for monitoring ureter pressure (UP). A small incision was made on the lower abdomen to provide access to the bladder and the left ureter. A small incision was made on the lower ureter nearby the bladder and insert the amino- 600 of about $4 \mathrm{~cm}$, then balloon was placed no closer to the top of the ureter than $2 \mathrm{~cm}$. We observed that ureter pressure increased gradually while the balloon was being inflated. When ureter pressure began to plateau, we observed that the pressure remained unchanged for about $10 \mathrm{~min}$. This we considered to be a successful model of ureteral obstruction. Finally, the left ureter was ligated along the outside wall of the bladder, and a small incision was made on the ureter under the balloon to insert a catheter (about $2 \mathrm{~mm}$ in diameter) to collect urine leaking around the balloon (Fig. 1).

\section{Experimental group}

After successful establishment of the animal model, the dogs were randomly divided into five groups: control group A $(n=5$, isoprenaline $10 \mu \mathrm{g} / \mathrm{kg}+$ saline $)$ and experimental groups B1 $(n=5$, isoprenaline $10 \mu \mathrm{g} / \mathrm{kg}+$ L-NAME $5 \mathrm{mg} / \mathrm{kg}), \mathrm{B} 2(n=5$, isoprenaline $10 \mu \mathrm{g} / \mathrm{kg}+$ L-NAME $10 \mathrm{mg} / \mathrm{kg})$, B3 $(n=5$, isoprenaline $10 \mu \mathrm{g} / \mathrm{kg}$

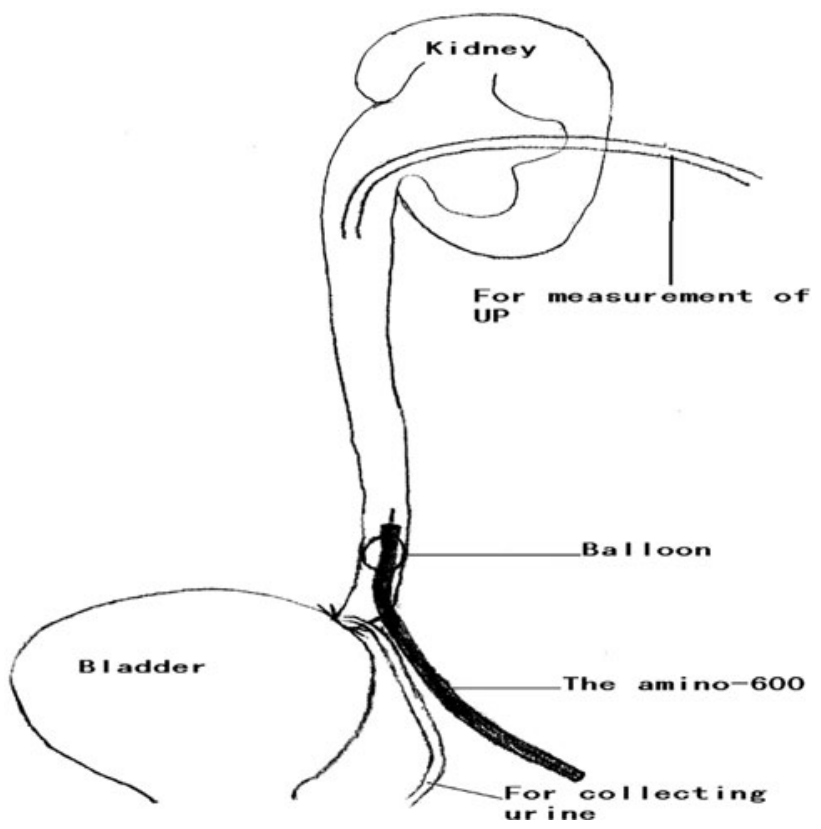

Fig. 1 Measuring the concentration of NO and pressure in the ureter

+ L-NAME $20 \mathrm{mg} / \mathrm{kg})$, and B4 $(n=5$, isoprenaline $10 \mu \mathrm{g} / \mathrm{kg}+$ L-NAME $30 \mathrm{mg} / \mathrm{kg}$ ).

\section{Administration}

First, the models were pre-treated intravenously with different doses of L-NAME (non-selective nitric oxide synthase inhibitor) to inhibit nitric oxide synthase (NOS), and 10 min later, each of them was administered an intravenous dose of isoproterenol $(10 \mu \mathrm{g} / \mathrm{kg})$. Ureteral pressure and the concentration of $\mathrm{NO}$ in the ureteral urine [the concentration of NO was monitored with an NO monitor (model inNO-T, Innovative Instruments)] were measured simultaneously. Each sensor was calibrated using pure, NO-saturated water. Briefly, this NO-saturated water was prepared by bubbling pure NO gas through oxygen-free pure water. Using a gastight syringe, $5 \mu \mathrm{L}$ of water was injected into well-stirred saline solution $(50 \mathrm{~mL})$ in which the $\mathrm{NO}$ sensor was immersed (final NO concentration: $190 \mathrm{nmol}$ ). The baseline ( 0 level) was set arbitrarily using the amperometric method, and, thus, it became possible to interpret changes in the current from the baseline as changes in NO concentration (nmol), and in the volume of the urine (UFv) leaking around the balloon.

Statistical analysis

The data are expressed as mean \pm standard deviation (Mean $\pm \mathrm{SD}$ ). A one-way ANOVA was used for the statistical analysis of multiple comparisons within each group. 
When a significant difference was detected, the data were further analyzed with Dunnett's test. A Student's $t$ test for unpaired data was used when comparisons were made between two groups. A value of $P<0.05$ was considered to indicate statistical significance.

\section{Results}

The animal models of acute ureteral obstruction were all created successfully

The equilibrium UP was $52.2 \pm 3.6 \mathrm{mmHg}(n=25)$ and the time required to reach the equilibrium after ureteral obstruction was $91.0 \pm 3.0 \min (n=25)$.

Concentration of NO in the acutely obstructed ureters of different groups

The concentration of NO and the total concentration for each experimental and control group shown in Fig. 2. After the administration of isoproterenol, the concentration of NO gradually increased and reached a peak value. Then, the concentration of NO gradually diminished, approaching the starting concentration. However, both the peak value and the total concentration of NO varied by group: groups A, B1, and B2 showed the highest values, while group B4 showed the lowest values. The peak values and the total concentration among groups A, B1, and B2 showed no statistically significant differences $(P>0.05)$ (Fig. 2).

\section{Changes in UP in different groups}

About 2 min after the administration of isoproterenol, we were able to observe the maximum rate of change in the UP in each group: group A: $67.48 \pm 5.62 \%$, group B1: $70.01 \pm 5.21 \%$, group B2: $64.34 \pm 4.52 \%$, group B3: $54.39 \pm 4.44 \%$, group B4: $44.67 \pm 2.02 \%$. Groups B3 and $\mathrm{B} 4$ showed significantly lower rates of change than groups A, B1 and B2 did $(P<0.05)$. Group B4's rate of change was lower than that of groups B3 $(P<0.05)$, demonstrating that the rate of change in UP was inversely proportional to the amount of L-NAME given to each group. However, there was no statistically significant difference $(P>0.05)$ between groups A, B1, and B2. From the pressure-time curve shown in Fig. 3, it can be observed that UP declined rapidly reaching its minimum value about 2 min after the administration of isoproterenol, then gradually recovered, first at a moderate pace and then more slowly, eventually holding steady. The time that it took to return to and maintain a stable level of UP was different for each group, but directly related to the size of the dose of L-NAME. Groups B3 and B4 took more time than groups A, B1 or B2
$(P<0.05)$; group B4 took longer than groups B3 $(P<0.05)$. Groups A, B1 and B2 were not significantly different from each other in this respect $(P>0.05)$. We also observed that during the time that elapsed between the injection of isoproterenol to the maintenance of a stable level of UP, the UP of groups B3 and B4 was significantly higher than that of groups A, B1 or B2 $(P<0.05)$ and that of group B4 was higher than that of group B3 $(P<0.05)$ but those of groups A, B1 and B2 were not obviously different from each other $(P>0.05)$ (Fig. 3).

The volume of the urine flow (UFv) leaking from the balloon in different groups

For every group, the volume of leaked urine was collected for 20 min before ureteral obstruction was established and during five consecutive 20 min periods after obstruction and injection of L-NAME for a total of $100 \mathrm{~min}$. We compared measurements of urine flow volume (UFv) from the unobstructed $20 \mathrm{~min}$ and found no statistically significant difference between the groups $(P>0.05)$. After the administration of L-NAME, UFv gradually increased over time, with the exception that the first 20 min post-injection period saw more leakage than the second 20 min postinjection period in all groups $(P<0.05)$, the other time periods: "the third 20 min post-injection", "the fourth 20 min post-injection", and "the fifth 20 min post-injection" in each group $(P<0.05)$. For every $20 \mathrm{~min}$ period after the injection of L-NAME, UFv was found to be inversely proportional to the dose L-NAME: groups A, B1, and $\mathrm{B} 2$ showed significantly higher UFv than groups $\mathrm{B} 3$ or B4 $(P<0.05)$; and group B3 showed higher UFv than group $\mathrm{B} 4(P<0.05)$; but among groups $\mathrm{A}, \mathrm{B} 1$, and $\mathrm{B} 2$, there was no statistically significant difference $(P>0.05)$ (Fig. 4).

\section{Discussion}

The animal model of acute ureteral obstruction

Acute ureteral obstruction can lead to the changes in pressure inside the ureter, and then to ureter function disorders. In this experiment, we created an animal model: via the application of a balloon embedded in the lower ureter, which was expanded to cause complete ureter obstruction [8]. This model provides great advantages over previous techniques [9]. We observed that ureteral pressure increased gradually alongside the amount of liquid inside the balloon. In the end, UP reached stable levels in all test subjects. In this experiment, we observed that the average of ureter pressure was $52.2 \pm 3.6 \mathrm{mmHg}(n=25)$ when balanced. The average time it took to reach this level was 
Fig. 2 NO concentration in acutely obstructed ureters in different groups

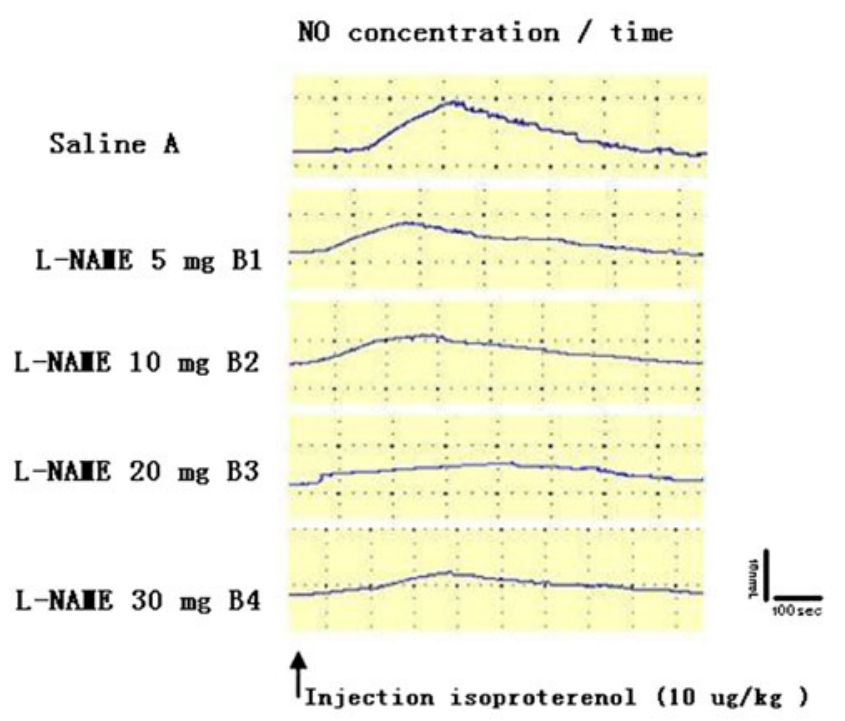

Total of NO concentration in different groups

Peak value of NO concentration in differernt groups

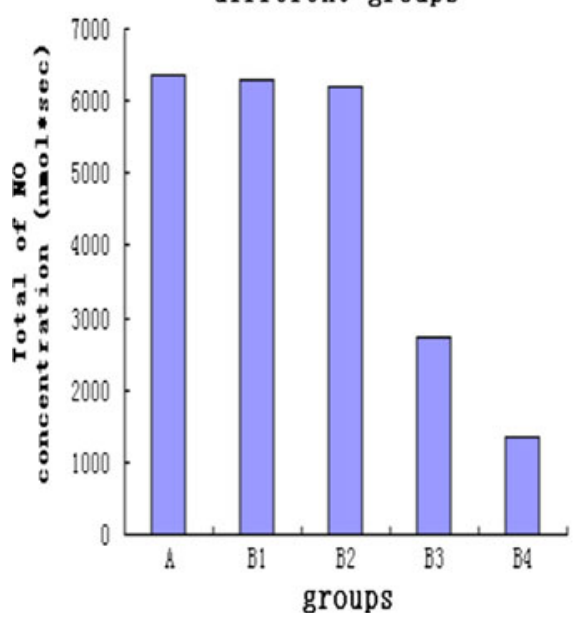

can determine that this model creates situations very similar to clinical cases of lower ureteral obstruction. In this model, subjects were pre-treated with different doses of L-NAME (nitric oxide synthase inhibitor) by intravenous injection and then given a constant dose of isoprenaline to stimulate ureteral smooth muscle relaxation. After administration, we observed changes of the ureteral pressure, monitored the concentration of NO in ureteral urine using the inNO-T nitric oxide monitoring system, observed the relationship between NO concentration and the ureteral pressure, and learned the role that NO plays in acute obstructive ureteral recanalization.

Fig. 3 Changes in ureter pressure (UP) in different groups

$90.6 \pm 6.5 \min (n=25)$. During the pre-experiment, we observed that UP could go to a maximum of approximately $120 \mathrm{~min}$ without undergoing any changes, which is in accordance with the previous reports $[10,11]$. From this we
The role of NO on the pressure of the acute obstructive ureter

Morrissey et al. found in an animal experiment that ureteral pressure increased significantly after administration of 
Fig. 4 Volume of the urine (UFv, ml) leaking from around the balloon in different groups

\begin{tabular}{|c|c|c|c|c|c|}
\hline & \multicolumn{4}{|c|}{ group } & \\
\hline & A (Saline) & B1 (L-HAUE $5 \mathrm{mg}$ ). & B2. (L-NAME $10 \mathrm{mg}$ ) & B3 (L-HAME $20 \mathrm{mg})+$ & B4 (L-NAHE $30 \mathrm{mg}$ ) \\
\hline The unobstructed 20 minutes & $2.03 \pm 0.14$ & $2.04 \pm 0.28$ & $2.03 \pm 0.17$ & $2.03 \pm 0.15$ & $2.05 \pm 0.15$ \\
\hline The first 20 minutes post-injection period & $1.20 \pm 0.12$ & $1.18 \pm 0.12$ & 1. $16 \pm 0.12$ & $0.82 \pm 0.09$ & $0.58 \pm 0.06$ \\
\hline The second 20 minutes post-injection period & $1.02 \pm 0.12$ & $1.01 \pm 0.10$ & $1.02 \pm 0.14$ & $0.68 \pm 0.06$ & $0.48 \pm 0.04$ \\
\hline The third 20 minutes post-injection period & $1.26 \pm 0.09$ & $1.27 \pm 0.09$ & $1.27 \pm 0.02$ & $0.74 \pm 0.05$ & $0.51 \pm 0.05$ \\
\hline The fouth 20 minutes post-injection period & $1.63 \pm 0.08$ & $1.65 \pm 0.11$ & $1.62 \pm 0.03$ & $0.89 \pm 0.05$ & $0.62 \pm 0.07$ \\
\hline The fifth 20 minutes post-injection period & $1.80 \pm 0.08$ & $1.82 \pm 0.08$ & $1.84 \pm 0.07$ & $1.06 \pm 0.05$ & $0.75 \pm 0.04$ \\
\hline
\end{tabular}

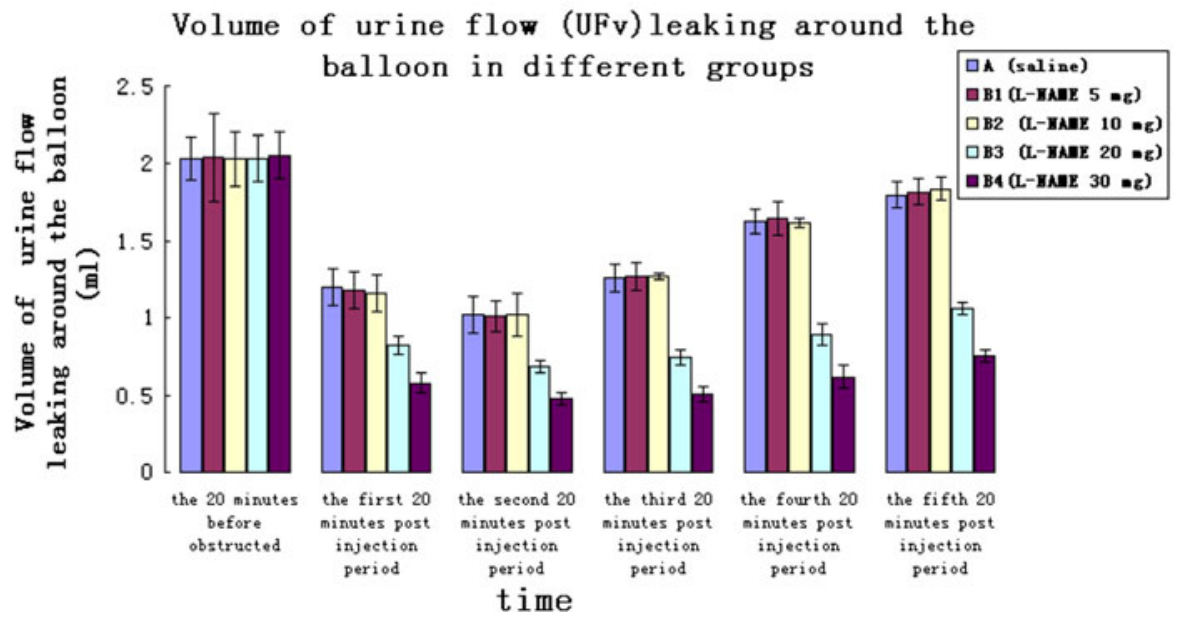

NOS inhibitors, while the concentration of nitrite in ureteral urine was significantly lower than normal [12]. However, after administering nitric oxide and synthesis of L-arginine, they found that the ureteral pressure decreased significantly, and that the concentration of nitrite in ureteral urine was increased [12]. From this, they speculated that NOS inhibitors and NOS can regulate the relaxation of ureteral smooth muscle by altering the concentration of $\mathrm{NO}$ and so control ureteral pressure [12]. Quayle et al. found that drugs stimulated the ureteral smooth muscle to relax and that this was caused either by preventing calcium ions from entering smooth muscle cells or by reducing the sensitivity of calcium channels [13]. As a result, this reduced the concentration of calcium ions in the smooth muscle cells and eased smooth muscle contraction [13]. Iselin et al. found exogenous NO to increase cyclic guanosine monophosphate (cGMP) levels and promote smooth muscle relaxation in isolated strips of pig ureteral smooth muscle [14]. Weiss et al. observed that ureteral peristalsis became significantly reduced after administration of nicorandil, and speculated that this phenomenon may result from the action of endothelial NOS on the ureter, and the subsequent increase in NO, that NO inhibited calcium ion channels, then reduced the concentration of intracellular calcium ions, then inhibited ureteral smooth muscle contractile function [15]. Holzmann et al. proposed that the mechanism of this might be that NO first diffuses into smooth muscle cells to activate guanylate cyclase (GC), which can activate cGMP [16]. High concentrations of
cGMP can activate the $\mathrm{K}^{+}-\mathrm{ATP}$ or $\mathrm{K}^{+}-\mathrm{Ca}^{2+}$ channels, and lead to $\mathrm{K}^{+}$influx and $\mathrm{Ca}^{2+}$ outflow, reducing the concentration of intracellular calcium ions, activating smooth muscle relaxation. Smooth muscle relaxation itself can activate NOS, stimulating the release of more NO.

In our experiment, when isoproterenol combined with adrenergic receptors, it leads to muscle relaxation (there are affluent adrenergic receptors on canine ureteral smooth muscle [8], when exposed to $\beta$-adrenergic agonists, they stimulate ureteral smooth muscle relaxation). This then caused NOS activation and the release of more NO. When the concentration of NO increased, we extrapolated that the concentration of cGMP on the ureteral smooth muscle increased as well. This inhibited calcium ion flow into the muscle cells, resulting in smooth muscle relaxation and decrease in ureteral pressure. The more NO, the greater the range of relaxation observed in the ureteral smooth muscle, and the greater the decrease in ureteral pressure. When the ureteral pressure reduced and dropped to a certain level, the urine will leak out around the edge of the balloon. In this experiment, we pre-treated subjects from each group with different doses of L-NAME to inhibit nitric oxide synthase activation in order to inhibit the release of NO.

Ureteral pressure became steady after the animal model of acute ureteral obstruction was successfully established, and the ureteral smooth muscle was in a quiescent state. During this time, we observed that the concentrations of NO inside the ureter were very low. However, a certain period after the injection of isoproterenol, we found that 
the concentration of NO increased sharply in each group. We speculated that this might be result of activation of NOS stemming from the isoproterenol combining with adrenergic receptors. Moreover, we observed that the greater the dose of L-NAME, the more NOS was inhibited, and the lower the amount of NO. For example, groups A, which received no L-NAME, saw the highest peak concentration of $\mathrm{NO}$, the greatest total concentration of NO, and the largest rate of change in ureteral pressure. The urine leaking around the edge of the balloon was also the highest in volume. The peak and the total concentrations of NO, UP, and UFv were not of great difference among groups B1, B2, and A, all of which received low or no doses of L-NAME. However, when the pre-treated dose of L-NAME was larger, such as with groups B3 (20 mg L-NAME), and B4 (30 mg L-NAME), more nitric oxide synthase was inhibited, and less NO was released. According to the theory proposed by Holzmann et al., we speculated that it (L-NAME) reduced the concentrations of cGMP when less NO was released, thus inhibiting $\mathrm{K}^{+}-\mathrm{ATP}$ and $\mathrm{K}^{+}-\mathrm{Ca}^{2+}$ channels, and reducing $\mathrm{K}^{+}$influx and $\mathrm{Ca}^{2+}$ outflow, so that more calcium ions remained in the muscle cells [16]. As a result, ureteral smooth muscle relaxation was inhibited, and ultimately the rate of change in ureteral pressure was minimized, finally resulting in a reduction in the amount of urine leaking from the balloon.

\section{The effects of NO on UFv}

During the first $100 \mathrm{~min}$ after the injection of isoprenaline $(10 \mu \mathrm{g} / \mathrm{kg})$, we found that UFv increased gradually, showing the least leakage in the second 20 min after the establishment of the obstruction and more in each $20 \mathrm{~min}$ period after that. It may be that drug-induced smooth muscle relaxation may cause urine cached above the obstructed site to drain out. However, because the total amounts of urine flow in groups B1 (L-NAME $5 \mathrm{mg}$ ) and B2 (L-NAME $10 \mathrm{mg}$ ) were greater than those of groups B3 (L-NAME $20 \mathrm{mg}$ ) and B4 (L-NAME $30 \mathrm{mg}$ ), we speculated that this phenomenon was rather due to the action of L-NAME as an NOS enzyme inhibitor on nitric oxide synthase activation, reducing NO release, and resulting in the largest rate of change in ureteral pressure through controlling the $\mathrm{K}^{+}{ }_{-}$ATP or $\mathrm{K}^{+}{ }_{-} \mathrm{Ca} 2{ }^{+}$channels to inhibit the ureteral smooth muscle relaxation. In the end, the amount of urine leaking from the balloon was reduced. Moreover, in this experiment, we observed that the concentration of NO was greatest and the rate of change of ureteral pressure was largest during the first $20 \mathrm{~min}$ after injection, while the volume of the urine flow was the lowest at this time. Probably, the reason for this is that the UFv in the first 20 min had been partially collected from the remaining before the obstruction.
According to the data recorded during this experiment, it can be speculated that the relaxation of ureteral muscle and decreasing ureteral wall tension caused by NO may promote urine flow around incarcerated calculi. There may be decreased force of coaptation between the point of obstruction and the ureteral wall, which may actually decrease the pressure gradient across the obstructed site. This avenue of urine flow can cause a drop in UP or even permit passage of a kidney stone.

\section{Conclusion}

In general, the pressure in an acutely obstructed ureter and the concentration of NO released by the nearby tissue will be inversely proportional to one another. The greater the concentration of $\mathrm{NO}$, the greater the rate of change in ureteral pressure. In clinical situations, we have often encountered patients with acutely painful ureteral stones. We believe that taking measures to quickly increase the concentration of NO inside the ureter would reduce the pressure inside ureter and cause the stone to be discharged. It is even possible that the administration of drugs to stimulate the relaxation of ureteral smooth muscle and the release of NO may facilitate the residual stones to discharge after ureteroscopic lithotripsy or extracorporeal shock wave lithotripsy. Nevertheless, because this is only an animal experiment, at present, clinical evidence is still lacking. Effective drugs that solely and specifically increase the concentration of NO inside the human ureter particularly drugs that do not affect the cardiovascular system have yet to be identified and confirmed. Further study is needed to establish to any useful degree.

Open Access This article is distributed under the terms of the Creative Commons Attribution Noncommercial License which permits any noncommercial use, distribution, and reproduction in any medium, provided the original author(s) and source are credited.

\section{References}

1. Biancani P, Zabinski MP, Weiss RM (1976) Time course of ureteral changes with obstruction. Am J Physiol 231:393-398

2. Crowley AR, Byrne JC, Darracott Vaughan E et al (1990) The effect of acute obstruction on ureteral function. J Urol 143:596-599

3. Ehren I, Adolfsson J, Wiklund NP (1994) Nitric oxide synthase activity in the human urogenital tract. Urol Res 22(5):287-290

4. Stiefl CG, Ukertl S, Trussl MC, Beckerl AJ et al (1996) A possible role for nitric oxide in the regulation of human ureteral smooth muscle tone in vitro. Urol Res 24(6):333-337

5. Knerr I, Dittrich K, Miller J et al (2001) Alteration of neuronal and endothelial nitric oxide synthase and neuropeptide $\mathrm{Y}$ in congenital ureteropelvic junction obstruction. Urol Res 29(2): 134-140 
6. Urchgott RF, Zawadzki JV (1980) The obligatory role of endothelial cell in relaxation of arterial smooth muscle by acetylcholine. Nature 288:373-376

7. Iselin CE, Alm P, Schaad NC, Larsson B, Graber P, Andersson KE (1994) Nitric oxide inhibits contraction of isolated pig ureteral smooth muscle. J Urol 155:763-767

8. Murakami Makoto, Tomiyama Yoshitaka, Hayakawa Kohichi et al (2000) Effects of $\beta$-Adrenergic stimulation on the acutely obstructed ureter in dogs. The J of Pharm and Exp Ther 292(1): $67-75$

9. Stower MJ, Clark AG, Wright JW, Hardcastle JD (1986) The effect of ritodrine and glucagon on the acutely obstructed canine ureter. Urol Res 14:37-40

10. Darracott Vaughan E, Shenasky JH II, Gillenwater JY (1971) Mechanism of acute hemodynamic response to ureteral occlusion. Invest Urol 9:109-118

11. Moody TE, Vaughan ED, Gillenwater JY (1975) Relationship between renal blood flow and ureteral pressure during 18 hours of total unilateral ureteral occlusion. Invest Urol 13:246-251
12. Morrissey JJ, Ishidoya S, MoCracken R and Klahr S (1996) Nitric oxide generation ameliorates the tubulointerstitial fibrosis of obstructive nephropathy. J Am Soc Nephrol 7:2202-2212

13. Quayle JM, Nelson MT and Standen NB (1997) ATP-sensitive and inwardly rectifying potassium channels in smooth muscle. Physiol Rev 77:1165-1232

14. Iselin CE, Alm P, Schaad NC, Larsson B, et al (1994) Nitric oxide inhibits contraction of isolated pig ureteral smooth muscle. J Urol 155:763-767

15. Weiss R, Mevissen M, Daniela S et al (2002) Inhibition of human and pig ureter motility in vitro and in vivo by the $\mathrm{K}^{+}$channel openers PKF 217-744b and nicorandil. Pharmacology 302(2): 651-658

16. Holzmann S (1983) Cyclic GMP as possible mediator of coronary arterial relaxation by nicorandil (SG-75). J Cardiovasc Pharmacol $5: 364-370$ 